Article abstract-Clinical criteria for the diagnosis of Alzheimer's disease include insidious onset and progressive impairment of memory and other cognitive functions. There are no motor, sensory, or coordination deficits early in the disease. The diagnosis cannot be determined by laboratory tests. These tests are important primarily in identifying other possible causes of dementia that must be excluded before the diagnosis of Alzheimer's disease may be made with confidence. Neuropsychological tests provide confirmatory evidence of the diagnosis of dementia and help to assess the course and response to therapy. The criteria proposed are intended to serve as a guide for the diagnosis of probable, possible, and definite Alzheimer's disease; these criteria will be revised as more definitive information becomes available.

\title{
Clinical diagnosis of Alzheimer's disease: Report of the NINCDS-ADRDA Work Group* under the auspices of Department of Health and Human Services Task Force on Alzheimer's Disease
}

\author{
Guy McKhann, MD; David Drachman, MD; Marshall Folstein, MD; Robert Katzman, MD; \\ Donald Price, MD; and Emanuel M. Stadlan, MD
}

\begin{abstract}
Alzheimer's disease is a brain disorder characterized by a progressive dementia that occurs in middle or late life. The pathologic characteristics are degeneration of specific nerve cells, presence of neuritic plaques, and neurofibrillary tangles. Alterations in transmitter-specific markers include forebrain cholinergic systems, and, in some cases, noradrenergic and somatostatinergic systems that innervate the telencephalon.

A Work Group on the Diagnosis of Alzheimer's Disease was established by the National Institute of Neurological and Communicative Disorders and Stroke (NINCDS) and the Alzheimer's Disease and Related Disorders Association (ADRDA). The group intended to establish and to describe clinical criteria for the diagnosis of Alzheimer's disease of particular importance for research protocols and to describe approaches that would be useful for assessing the natural history of the disease. The need to refine clinical diagnostic criteria has been emphasized because $20 \%$ or more of cases with the clinical diagnosis of Alzheimer's disease are found at autopsy to have other conditions and not Alzheimer's disease. Moreover, therapeutic trials can be meaningfully compared only if uniform criteria are used for diagnosis and response to treatment.
\end{abstract}

The need for this report was suggested by the National Advisory Council of the NINCDS. The report has been reviewed by workshop participants, representatives of the National Advisory Neurological and Communicative Disorders and Stroke Council, representatives of the ADRDA, and designated reviewers representing professional societies concerned with the diagnosis of Alzheimer's disease. (For list of professional societies and designated reviewers, see page 943.)

The report was developed by subgroups that addressed medical history, clinical examination, neuropsychological testing, and laboratory assessments; the report was then discussed in plenary session. Based on a consensus of the participants, criteria were developed to serve as a clinical basis for diagnosis. These criteria should be useful also for comparative studies of patients in different kinds of investigations, including case control studies, therapeutic trials, evaluation of new diagnostic laboratory tests, and clinicopathologic correlations.

The criteria are not yet fully operational because of insufficient knowledge about the disease. The criteria are compatible with definitions in the current Diagnostic and Statistical Manual of Mental Disorders (DSM III) and in the International Classification of Diseases. These criteria must be regarded as tentative and subject to change. Additional longitudinal studies, confirmed by autopsy, are necessary to establish the validity of these criteria in com-

*For Work Group Participants and Affiliations, see page 943.

Accepted for publication March 20, 1984.

Address correspondence and reprint requests to Dr. Stadlan, 7550 Wisconsin Avenue, Federal Building, Room 700, Bethesda, MD 20205. 
I. The criteria for the clinical diagnosis of PROBABLE Alzheimer's disease include:

dementis established by clinical examination and documented by the Mini-Mental Test,' Blessed Dementia Scale,"' or some similar examination, and confirmed by neuropsychological tests;

deficits in two or more areas of cognition;

progressive worsening of memory and other cognitive func tions;

no disturbance of consciousness;

onset between ages 40 and 90 , most often after age 65 ; and

absence of systemic disorders or other brain diseases that in and of themselves could account for the progressive deficits in memory and cognition

II. 'The diagnosis of PROBABLE Alzheimer's disease is supported by:

progressive deterioration of specific cognitive functions such as language (aphasia), motor skills (apraxia), and perception (ag. nosia);

impaired activities of daily living and aitered patterns of behavior;

family history of similar disorders, particularly if confirmed neuropathologically; and

laboratory results of:

normal lumbar puncture as evaluated by standard techniques,

normal pattern or nonspecific changes in EEG, such as increased slow-wave activity, and

evidence of cerebral atrophy on CT with progression documented by serial observation.

III. Other clinical features consistent with the diagnosis of PROBABLE Alzheimer's disease, after exclusion of causes of dementia other than Alzheimer's disease, include:

plateaus in the course of progression of the illness;

associated symptoms of depression, insomnia, incontinence. delusions, illusions, hallucinations, catastrophic verbal, emo tional, or physical outbursts, sexual disorders, and weight loss; other neurologic abnormalities in some patients, especially with more advanced disease and including motor signs such as increased muscle tone, myoclonus, or gait disorder;

seizures in advanced disease; and

CT normal for age.

IV. Features that make the diagnosis of PROBABLE Alzheimer's disease uncertain or unlikely include:

sudden, apoplectic onset;

focal neurologic findings such as hemiparesis, sensory loss, visual field deficits, and incoordination early in the course of the illness; and

seizures or gait disturbances at the onset or very eariy in the course of the illness.

V. Clinical diagnosis of POSSIBLE Alzheimer's disease:

may be made on the basis of the dementia syndrome, in the absence of other neurologic, psychiatric, or systemic disorders sufficient to cause dementia, and in the presence of variations in the onset, in the presentation, or in the clinical course;

may be made in the presence of a second systemic or brain disorder sufficient to produce dementia, which is not considered to be the cause of the dementia; and

should be used in research studies when a single, gradually progressive severe cognitive deficit is identified in the absence of other identifiable cause.

VI. Criteria for diagnosis of DEFINITE Alzheimer's disease are:

the clinical criteria for probable Alzheimer's disease and

histopathologic evidence obtained from a biopsy or autopsy.

VII. Classification of Alzheimer's disease for research purposes should specify features that may differentiate subtypes of the disorder, such as:

familial occurrence;

onset before age of 65 ;

presence of trisomy-21; and

coexistence of other relevant conditions such as Parkinson's disease. parison with other criteria such as DSM III.

Criteria for dementia syndrome. Dementia is the decline of memory and other cognitive functions in comparison with the patient's previous level of function as determined by a history of decline in performance and by abnormalities noted from clinical examination and neuropsychological tests. A diagnosis of dementia cannot be made when consciousness is impaired by delirium, drowsiness, stupor, or coma or when other clinical abnormalities prevent adequate evaluation of mental status. Dementia is a diagnosis based on behavior and cannot be determined by computerized tomography, electroencephalography, or other laboratory instru- ments, although specific causes of dementia may be identified by these means.

Criteria for Alzheimer's disease. Alzheimer's disease is a progressive, dementing disorder, usually of middle or late life. The clinical criteria for the diagnosis of PROBABLE, POSSIBLE, and DEFINITE Alzheimer's disease are outlined in table 1. A clinical diagnosis of probable Alzheimer's disease can be made with confidence if there is a typical insidious onset of dementia with progression and if there are no other systemic or brain diseases that could account for the progressive memory and other cognitive deficits. Among the disorders that must be excluded are manic-depressive disorder, Parkinson's 
disease, multi-infarct dementia, and drug intoxication; less commonly encountered disorders that may cause dementia include thyroid disease, pernicious anemia, luetic brain disease and other chronic infections of the nervous system, subdural hematoma, occult hydrocephalus, Huntington's disease, Creutzfeldt-Jakob disease, and brain tumors.

A diagnosis of definite Alzheimer's disease requires histopathologic confirmation. A clinical diagnosis of possible Alzheimer's disease may be made in the presence of other significant diseases, particularly if, on clinical judgment, Alzheimer's disease is considered the more likely cause of the progressive dementia. The clinical diagnosis of possible rather than probable Alzheimer's disease may be used if the presentation or course is somewhat aberrant. The information needed to apply these criteria is obtained by standard methods of examination: the medical history; neurologic, psychiatric, and clinical examinations; neuropsychological tests; and laboratory studies.

Medical history. A medical history should be taken from the patient and from an informant who is well acquainted with the affected individual. This approach is essential to establish a history of progressive deterioration and for identifying tasks that the patient can no longer perform adequately. A diary maintained by an observer may be very helpful in documenting changes in various functions. The history discloses abnormalities including impaired memory and other cognitive functions, impaired activities of daily living, alterations in mood, often delusions and illusions, and sometimes hallucinations. Common complaints of patients or families include forgetfulness about appointments or errands; inability to find the way to an accustomed destination; inability to use money and instruments of daily living such as a telephone; deterioration in work or homemaking performance; difficulty adapting to changes in the workplace; difficulties in dressing, reading, and writing; and inability to recognize previously familiar individuals.

Clinical examination. The clinical examination provides data to fulfill inclusionary and exclusionary criteria for the diagnosis of Alzheimer's disease and to document symptoms such as delusions or depression that identify subgroups of patients important both for research studies and for patient care. Mental status testing, an essential component of the clinical examination, includes specific assessment of orientation, registration, attention, calculation, recent recall, naming, repeating, understanding, reading, writing, and ability to draw or copy. Because cognitive impairment may occur in depressive syndromes, it is important to inquire about affective state and depressive symptoms, such as disturbed sleep and weight loss, before diagnosing Alzheimer's disease. Inquiry specifically about the presence of delusions and hallucinations is needed to identify subgroups. Both symptoms may be experienced in a variety of neuropsychiatric disorders, which may or may not have known organic substrates.

Quantitative aids to the clinical examination include the Mini-Mental State Examination ${ }^{1}$ for cognitive screening; the Blessed Dementia Scale ${ }^{2}$ for clinical symptoms and social function; the Hamilton Depression Scale ${ }^{3}$ for severity of depression; the Present State Examination ${ }^{4}$ for anxiety, depression, delusions, and hallucinations; and the Hachinski Scale $^{5,6}$ for estimating the likelihood of multi-infarct dementia. A complete psychiatric evaluation is needed to exclude the various psychiatric disorders.

Complete examination of sensory and motor systems (including cranial nerves, tone, reflexes, coordination, gait, and proprioception) is needed to exclude other neurologic disorders. In early stages, patients are alert and free of other neurologic changes related to the dementia except for the occasional presence of snout reflex, jaw jerk, rigidity, or myoclonus, all of which may be encountered in nondemented elderly people. As the disease progresses, some patients become apathetic or show irritability, agitation, paranoid ideas, sleep disorders, or incontinence. In the very advanced stages, patients may become mute and lose all ability to communicate.

Neuropsychological testing. Neuropsychological tests may provide additional information for the diagnosis of dementia. Because there are no normative population standards for many of these tests, abnormal performance can be determined only by comparison with a normal control group matched for age, sex, and local education. A score falling in the lowest fifth percentile of an individual's normal control group may be designated as "abnormal." One or more abnormal scores will identify an individual for research purposes who is highly likely to be cognitively impaired. Progressive worsening can be established by comparison with the patient's previous performance on these tests. Although there is continued debate about the tests that best measure these functions, the Work Group did make some suggestions (table 2).

Similar series of tests can be used to assess less severely affected patients by increasing the complexity of the neuropsychological tests. Further modification in the test procedure may be needed to detect impairment in highly intelligent patients. Confirmation of the dementia syndrome by neuropsychological tests should be based on measurable abnormalities in two or more aspects of cognition.

In longitudinal assessment, many patients with Alzheimer's disease show progressive loss of recent memory followed by disorders of language, praxis, or visual perception. In some patients with Alzheimer's disease, however, the first symptoms are difficulty in finding words, impaired visual perception, or apraxia, with memory impairment and other symptoms and signs appearing later.

Although neuropsychological tests are presently used primarily to provide confirmatory evidence for 
Table 2. Neuropsychological evaluation

The major cognitive processes that are impaired in Alzheimer's disease, with examples of the kinds of tests used to assess these functions, include:

orientation to place and time, graded by a test such as the Mini-Mental State Examination';

memory evaluated by tests such as a free-recall test ${ }^{\top}$ of concrete nouns, a 3-4 paired-associate learning test (verbal and nonverbal) by use of a recognition paradigm, the Recognition Span Test, ${ }^{8}$ and the BrownPeterson Distractor Test ${ }^{9111}$ (stopping the task when the patient fails or begins to produce the distractor instead of the stimulus trigrams);

language skills tested by examination of verbal fluency of the semantic or category type, with the examiner writing responses, and by other tests such as the Boston Naming Test" (preferably one of the abbreviated forms), the Boston Diagnostic Aphasia Examination,,$^{12}$ the Western Aphasia Test, ${ }^{1: 3}$ and the Token Test $^{1+\cdot 16}$ with Reporter's Test ${ }^{17}$;

praxis evaluated by tests ${ }^{14}$ such as those in which the patient copies a drawing (cube, daisy, clock, or house) or performs the block design subtest of the Wechsler Adult Intelligence Scale ${ }^{19}$;

attention monitored by tests such as a reaction-time $\operatorname{task}^{20}$ or by the Continuous-Performance Test ${ }^{21}$;

visual perception studied by use of a variety of tasks, such as the Gollin Incomplete-Pictures Test ${ }^{22}$ and the Hooper Test ${ }^{2: 3}$;

problem-solving skills determined by tests such as the Wisconsin Card Sorting Test ${ }^{2425}$ or The Poisoned Food Problem Task of Arenberg ${ }^{26.2}$; and

social function, activities of daily living, ${ }^{24,239}$ and instrumental activity of daily living; ${ }^{311}$ assessed by methods similar to those described in the Philadelphia Geriatrics Center Forms. ${ }^{31}$

the diagnosis of dementia, these tests are valuable for determining patterns of impairment, for assessing changes in impairment over time and after drug treatment or rehabilitation, and for establishing correlations of abnormal performance with laboratory and neuropathologic examinations.

Laboratory assessments. Clinical assessment and neuropsychological tests provide information to meet the criteria for clinically probable Alzheimer's disease. At present, there are no specific diagnostic laboratory tests for Alzheimer's disease, but some tests can enhance diagnostic accuracy by identifying other causes of the dementia syndrome. Moreover, as suggested by the Work Group, the laboratory approaches described below used quantitatively in longitudinal studies should help to clarify the natural history of Alzheimer's disease, possibly provide information needed in subtyping the disease, and permit measurement of efficacy of therapeutic interventions. Some of these techniques, particularly positron emission tomography, are strictly investigative tools and not readily available outside of research institutions.

Electrophysiologic methods. The EEG of some patients with Alzheimer's disease shows increased slow-wave activity that may become more pronounced with progression of the disease. Evoked potentials (EP) are brain waves associated with sensory or other events that may be auditory, somatosensory, or visual. Endogenous or cognitive potentials, such as P300, are thought to reflect speed of cognition. The latency of P300 is altered with age, and there appears to be an increased latency of P300 potentials in 50 to $80 \%$ of patients with Alzheimer's disease compared with age-matched control subjects. These changes occur in different dementias and are not specific to Alzheimer's disease. The P300 wave, however, is normal in depressive syndromes and may therefore be useful in differentiating the dementia of Alzheimer's disease from the dementia of depressive syndromes, particularly when adequate normal data become available.

Computerized tomography. CT is useful in the diagnosis of Alzheimer's disease because it permits the exclusion of other disorders such as subdural hematoma, brain tumor, hydrocephalus, and dementia associated with vascular disease. The technique can delineate gyri and sulci and quantitate tissue densities, ventricular size, CSF volume, and brain mass. In Alzheimer's disease, the volume of the ventricular system and the width of the third ventricle are increased, gyri are narrowed, and sulci are widened; however, these general patterns may not be particularly useful as diagnostic criteria in individual cases. Furthermore, available data do not indicate how well a qualitative observation correlates with the magnitude of cognitive abnormality or with evidence of progression of disease. There is a pressing need for quantitative CT studies of Alzheimer's disease patients during the course of disease and for correlation of CT images with clinical signs, neuropsychological test results, and autopsy findings.

Regional cerebral blood flow. Measurement of regional cerebral blood flow (rCBF), including ${ }^{133}$ xenon clearance, may help differentiate Alzheimer's disease and dementia associated with cerebrovascular disease. In multi-infarct dementia (MID), early changes include decreased autoregulation; in the later stages of MID, rCBF and oxygen consumption are decreased. In patients who have Alzheimer's disease, rCBF and cerebral metabolic rate are decreased; but $\mathrm{A}-\mathrm{V}$ differences, carbon dioxide responses, and autoregulation are preserved.

Positron emission tomography. Positron emission tomography (PET) is a research technique that allows quantitative assessment of the rate of glucose utilization, oxygen consumption, and rCBF. With some isotopes, these characteristics can be assessed during neuropsychological testing; moreover, ${ }^{11} \mathrm{C}$ markers may permit the use of retest paradigms. Early reports suggest that rCBF determined by PET may be reduced in areas of encephalomalacia. In contrast, most patients with Alzheimer's disease show cerebral hypometabolism when compared with 
age-matched controls. These changes correlate with disease severity and may be correlated with neuropsychological test performance. For example, speech impairment may be correlated with decreased activity in the left hemisphere, whereas impaired performance on spatial tasks may be more closely correlated with impaired activity in the right hemisphere. Different approaches may be necessary for delineating presynaptic and postsynaptic markers of transmitter systems, as recently achieved with PET images of the dopamine system. Since PET reveals a significant variation even among normal subjects, any changes may have to be severe to be detected. The value of PET studies in determining the stage of disease, in documenting progression, and in assessing the effects of treatment is unknown.

Magnetic resonance imaging. The proton nuclear magnetic resonance (NMR) image, or magnetic resonance imaging (MRI), reveals the demarcation of gray and white matter of the brain and has therefore proved useful in studies of demyelinating disorders. Although the method has not been applied systematically to the study of dementia, it has potential for differentiating between Alzheimer's disease, multi-infarct dementia, and low-pressure hydrocephalus. Information should soon be available about the usefulness of MRI in the diagnosis of Alzheimer's disease.

Examination of body fluids and nonneural tissues. In the diagnosis of Alzheimer's disease, studies of blood and CSF are helpful in excluding chronic infections, such as cryptococcal meningitis and syphilis, and other disorders. To date, definitive diagnostic information about Alzheimer's disease from blood or CSF has not been sought consistently, but CSF should be studied to demonstrate neurotransmitters, metabolites, and synthesizing and degradative enzymes. Other techniques, such as sophisticated radioimmunoassays with specific antibodies, may be useful for detecting markers of the disease, such as constituents associated with the development of neurofibrillary tangles and neuritic plaques. Specific abnormalities have not been detected in nonneural tissues.

\section{Acknowledgments}

The authors express their appreciation to Dr. George Eaves, NINCDS, for editorial and stylistic contributions, to Dr. Jason Brandt, Johns Hopkins University, and Dr. Asenath LaRue, UCLA, for verifying the accuracy of the bibliographic references, and to Ms. Paula J. Kirby, NINCDS, for patient and excellent secretarial services.

\section{Work Group Participants and Affiliations}

Guy McKhann, MD, Johns Hopkins University Medical School, Chairman; Francois Boller, MD, PhD, University of Pittsburgh; Nelson Butters, PhD, VA Medical Center and University of Cal- ifornia School of Medicine, San Diego; Suzanne Corkin, $\mathrm{PhD}$, Massachusetts Institute of Technology; Thomas Crook, PhD, Center for Studies of the Mental Health of the Aging, National Institute of Mental Health; David Drachman, MD, University of Massachusetts Medical Center; Steven Ferris, PhD, New York University; Marshall Folstein, MD, Johns Hopkins University Medical School; John H. Growdon, MD, Massachusetts General Hospital; Leonard Heston, MD, University of Minnesota Medical Center; Michael Huckman, MD, Rush-Presbyterian-St. Luke's Medical Center; Lissy F. Jarvik, MD, PhD, UCLA and West LAVA Medical Center, Brentwood; Robert Katzman, MD, Albert Einstein College of Medicine; Nancy E. Miller, $\mathrm{PhD}$, Center for Studies of the Mental Health of the Aging, National Institute of Mental Health; Edwin Olsen, MD, Veterans Administration Central Office, Washington, DC; Donald Price, MD, Johns Hopkins University Medical School; Stanley I. Rapoport, MD, National Institute on Aging; Arnold Starr, MD, University of California Medical Center, Irvine; Juan Taveras, MD, Massachusetts General Hospital; Eugene J. Oliver, $\mathrm{PhD}$, National Institute of Neurological and Communicative Disorders and Stroke; Lawrence Rubinstein, $\mathrm{PhD}$, National Institute of Neurological and Communicative Disorders and Stroke; Mr. William Weiss, National Institute of Neurological and Communicative Disorders and Stroke; Emanuel M. Stadlan, MD, National Institute of Neurological and Communicative Disorders and Stroke, Executive Secretary of the Work Group.

\section{Professional Societies and Designated Reviewers}

American Psychological Association: James L. Fozard, PhD, Veterans Administration Central Office.

American Neurological Association: David Drachman, MD, University of Massachusetts Medical Center; Robert Katzman, MD, Albert Einstein College of Medicine; Herbert Karp, MD, Emory University School of Medicine and Wesley Woods Center, Atlanta.

International Neuropsychological Society: Alfred W. Kaszniak, $\mathrm{PhD}$, University of Arizona.

American Academy of Neurology: David Drachman, MD, University of Massachusetts Medical Center; Robert Katzman, MD, Albert Einstein College of Medicine; Stuart A. Schneck, PhD, University of Colorado.

American Psychiatric Association: Lissy F. Jarvik, MD, PhD, University of California, Los Angeles and West LA.VA Medical Center, Brentwood; Peter V. Rabins, MD, Johns Hopkins Hospital; Charles E. Wells, MD, Vanderbilt University Medical Center; Jerome Yesavage, MD, Veterans Administration Hospital, Palo Alto.

American Geriatrics Society: John Blass, MD, Burke Rehabilitation Center and Cornell University Medical College; Charles E. Wells, MD, Vanderbilt University Medical Center.

\section{References}

1. Folstein M, Folstein S, McHugh PR. Mini-Mental State: a practical method for grading the cognitive state of patients for the clinician. J Psychiatric Res 1975;12:189-98.

2. Blessed $G$, Tomlinson BE, Roth $M$. The association between quantitative measures of dementia and of senile change in the cerebral grey matter of elderly subjects. Br J Psychiatry 1968;114:797-811.

3. Hamilton M. Development of a rating scale for primary depression illness. British Journal of Social and Clinical Psychology 1967;6:278-96.

4. Wing JK, Cooper JE, Sartorius N. The measurement and classification of psychiatric symptoms. Cambridge: 
Cambridge University Press, 1974.

5. Hachinski VC, Hiff LD, Zalkha E, et al. Cerebral blood flow in dementia. Arch Neurol 1975;32:632-7.

6. Hachinski VC, Lassen NA, Marshall J. Multi-infarct dementia: a cause of mental deterioration in the elderly. Lancet 1974;2:207-9.

7. Lezak MD. Neuropsychological assessment, 2nd ed. New York: Oxford University Press, 1983:422-9.

8. Moss MB. Assessment of memory in amnesic and dementia patients: adaptation of behavioral tests used with non-human primates. Presented at the 12 th annual meeting of the International Neuropsychological Society, Houston, TX, 1984.

9. Peterson LR, Peterson MJ. Short-term retention of individual verbal items. J Exp Psychol 1959;58:193-8.

10. Cermak LS, Butters N. The role of interference and encoding in the short-term memory deficits of Korsakoff patients. Neuropsychologia 1972;10:89-96.

11. Kaplan E, Goodglass H, Weintraub S. The Boston Naming Test. Boston: E. Kaplan and H. Goodglass, 1978.

12. Goodglass H, Kaplan E. The assessment of aphasia and related disorders. Philadelphia: Lea and Febiger, 1972.

13. Kertesz A. Aphasia and associated disorders. New York: Grune \& Stratton, 1979.

14. DeRenzi E, Vignolo LA. Token Test: a sensitive test to detect disturbances in aphasics. Brain 1962;85:665-78.

15. DeRenzi E, Faglioni P. Normative data and screening power of a shortened version of the Token Test. Cortex 1978;14:41-9.

16. Spellacy FJ, Spreen O. A short form of the token test. Cortex 1969;5:390-7.

17. DeRenzi E, Ferrari C. The Reporter's Test: a sensitive test to detect expressive disturbances in aphasics. Cortex 1978;14:279-93.

18. Borod JC, Goodglass H, Kaplan EF. Normative data on the Boston Diagnostic Aphasia Examination, Partial Lobe Battery, and the Boston Naming Test. J Clin Neuropsychol
$1980 ; 2: 209-15$.

19. Wechsler D. The Wechsler Adult Intelligence Scale - Revised Manual. New York: The Psychological Corporation, 1981

20. Benton A. Interactive effects of age and brain disease on reaction time. Arch Neurol 1977;34:369-70.

21. Rosvold HE, Mirsky AF, Sarason I, Bransome ED, Beck LH. A continuous performance test of brain damage. Journal of Consulting Psychology 1956;20:343-50.

22. Gollin ES. Developmental studies of visual recognition of incomplete objects. Percept Mot Skills 1960;11:289-98.

23. Hooper HE. The Hooper Visual Organization Test Manual. Los Angeles: Western Psychological Services, 1958.

24. Grant DA, Berg EA. A behavioral analysis of degree of reinforcement and ease of shifting to new responses in a Weigl-type card-sorting problem. J Exp Psychol 1948;38:404-11.

25. Milner B. Effects of different brain lesions on card sorting. Arch Neurol 1963;9:90-100.

26. Arenberg D. Concept problem-solving in young and old adults. J Gerontol 1968;23:279-82.

27. Arenberg D. A longitudinal study of problem-solving in adults. J Gerontol 1974;29:650-8.

28. Katz S, Ford AB, Moskowitz RW, Jackson BA, Jaffe MW. Studies of illness in the aged: the index of ALS, a standard measure of biological and psychosocial function. JAMA 1963;185:914-9.

29. Linn MW, Linn BS. Assessing activities of daily living in institutional settings. In: Crook T, Ferris S, Bartus R, eds. Assessment in geriatric psychopharmacology. New Canaan, CT: Mark Powley Associates, 1983:77-109.

30. Lawton MP, Brody EM. Assessment of older people: selfmonitoring and instrumental activities of daily living. Gerontologist 1969;9:179-86.

31. Lawton MP, Moss M, Fulcomer M, Kleban MH. A research and service-oriented multilevel assessment instrument. $J$ Gerontol 1982;37:91-9. 


\title{
Neurology
}

\author{
Clinical diagnosis of Alzheimer's disease: Report of the NINCDS-ADRDA Work Group* \\ under the auspices of Department of Health and Human Services Task Force on \\ Alzheimer's Disease \\ Guy McKhann, David Drachman, Marshall Folstein, et al. \\ Neurology 1984;34;939 \\ DOI 10.1212/WNL.34.7.939
}

This information is current as of July 1,1984

\section{Updated Information \&} Services

Citations

Permissions \& Licensing

Reprints including high resolution figures, can be found at: http://n.neurology.org/content/34/7/939.full

This article has been cited by 100 HighWire-hosted articles: http://n.neurology.org/content/34/7/939.full\#\#otherarticles

Information about reproducing this article in parts (figures,tables) or in its entirety can be found online at:

http://www.neurology.org/about/about_the_journal\#permissions

Information about ordering reprints can be found online:

http://n.neurology.org/subscribers/advertise

Neurology ${ }^{\circledR}$ is the official journal of the American Academy of Neurology. Published continuously since 1951, it is now a weekly with 48 issues per year. Copyright () 1984 by the American Academy of Neurology. All rights reserved. Print ISSN: 0028-3878. Online ISSN: 1526-632X.

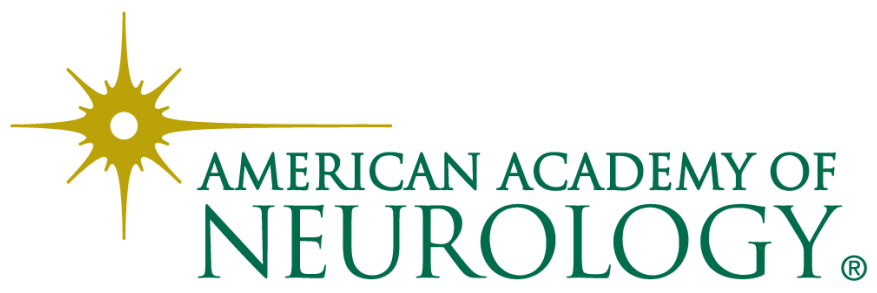

